\title{
NÃO HÁ MENTIRAS NEM VERDADES AQUI: REVISÃO NARRATIVA SOBRE A POPULAÇÃO BRASILEIRA EM SITUAÇÃO DE RUA
}

THERE ARE NO LIES OR TRUTHS HERE: NARRATIVE REVIEW ON THE BRAZILIAN POPULATION IN STREET SITUATION

NO HAY MENTIRAS TAMPOCO VERDADES AQUÍ: REVISIÓN NARRATIVA SOBRE LA POBLACIÓN BRASILEÑA EN SITUACIÓN DE CALLE

\section{Como Citar:}

Carmo LA, Góis JS. Não há mentiras nem verdades aqui: revisão narrativa sobre a população brasileira em situação de rua. Sanare (Sobral, Online). 2021; 20(2):79-87.

Descritores:

Pessoas em situação de rua; Política pública; Vulnerabilidade social; Revisão Sistemática.

Descriptors: Homeless people; Public policy; Social vulnerability; Systematic review.

Descriptores: Personas en situación de calle; Política pública; Vulnerabilidad social; Revisión Sistemática.

Submetido: $23 / 09 / 2020$ Aprovado: 16/09/2021

Autor(a) para Correspondência: Larissa de Andrade Carmo Escola de Saúde Pública do Ceará Endereço: Avenida B, 791 A. Prefeito Jose Walter. Fortaleza - Ceará CEP: 60750-010 E-mail: lalajate@gmail.com

\section{RESUMO}

o objetivo da pesquisa foi discutir sobre produções científicas que têm sido realizadas acerca das pessoas em situação de rua. Foi realizada uma revisão narrativa da literatura por meio do levantamento bibliográfico no sítio eletrônico Biblioteca Virtual em Saúde (BVS), entre junho e agosto de 2020. Doze publicações foram analisadas e organizadas em categorias para discutir três eixos temáticos: "Sinto muito, ela não mora mais aqui", no qual a população em situação de rua será caracterizada; "Olha o tumulto: Façam fila por favor", sobre as ações, o acesso e as políticas públicas; e "Não temos tempo a perder", voltado para a saúde mental e os Consultórios na Rua. Concluiu-se que os dados obtidos são genéricos, sendo necessário evidenciar essa lacuna e incentivar para que pesquisadores vejam a rua como fonte de relações e subjetividades que precisam ser examinadas e conhecidas, além de pressionar para que as políticas públicas direcionadas a essa população sejam implementadas com qualidade.

1. Graduada em Serviço Social. Especialista em Saúde da Família e Comunidade na modalidade Residência Multiprofissional. Escola de Saúde Pública do Ceará. E-mail: lalajate@gmail.com 0RCID: https://orcid.org/0000$\underline{0003-1590-6756}$

2. Graduada em Serviço Social. Mestra em Saúde Coletiva. Universidade Estadual do Ceará. E-mail: jhennifergois@ gmail.com ORCID: https://orcid.org/0000-0002-0386-2939

Cert. de Redação Científica: Central das Revisões. Edição de texto: Karina Maria M. Machado. Revisão de provas: Texto definitivo validado pelos (as) autores (as). 


\section{ABSTRACT}

The objective of the research was to discuss scientific productions that have been carried out regarding people living in street situation. A narrative review of the literature was carried out by means of a bibliographic survey on the website Biblioteca Virtual em Saúde (BVS), between June and August 2020. Twelve publications were analyzed and organized into categories to discuss three thematic axes: "I'm sorry she doesn't live here anymore", where the homeless population will be characterized; "Look at the commotion: line up, please", on actions, access, and public policies; and "We have no time to lose", focused on mental health and Street Clinics. We concluded that the data obtained were generic, and that it is necessary to highlight this gap and encourage researchers to see the street as a source of relationships and subjectivities that need to be examined and known. In addition to pressing for public policies aimed at this population to be implemented with quality.

\section{RESUMEN}

El objetivo de la investigación fue discutir acerca de producciones científicas que han sido realizadas sobre las personas en situación de calle. Fue realizada en una revisión narrativa de la literatura por medio del levantamiento bibliográfico en el sitio electrónico Biblioteca Virtual en Salud (BVS), entre junio y agosto de 2020. Doce publicaciones fueron analizadas y organizadas en categorías para discutir tres ejes temáticos: "Lo siento mucho, ella no vive aquí todavía", donde la población en situación de calle será caracterizada; "Mira el lío: hagan una cola, por favor", sobre las acciones, el acceso y las políticas públicas; y "No tenemos tiempo que perder", que se relaciona a la salud mental y los Consultorios en la Calle. Se concluye que los datos obtenidos son genéricos, siendo necesario evidenciar este vacio e incentivar para que investigadores vean la calle como fuente de relaciones de subjetividades que necesitan ser examinadas y conocidas. Además de presionar para que las politicas direccionadas a esa población sean implementadas con calidad.

\section{INTRODUÇÃ $O$}

Residentes da Saúde da Família e Comunidade do Programa da capital do estado do Ceará, no Nordeste brasileiro, foram encaminhados para a Unidade de Atenção Primária à Saúde localizada no bairro de Mucuripe. Este sendo um dos bairros da orla do município, conhecido por ser uma região de movimentação turística, embora seja um local em que há visualmente uma densa população em situação de rua.

Também era um dos pontos de acolhimento e abordagem do Projeto Corre Pra Vida, do Governo do Estado do Ceará, em que era oferecido em contêineres o acesso a chuveiros, sanitários e produtos de higiene, e funcionava como referência de apoio, como suporte de uma equipe interdisciplinar e de redutores de danos, com os quais os residentes realizaram uma parceria em que organizavam atividades e acolhiam a população que era encaminhada pelos profissionais do projeto, permitindo a criação de um laço.

Dessa forma, durante o cotidiano, conhecemos algumas pessoas desse grupo que buscaram atendimento na Unidade Básica de Saúde e cada uma trouxe uma história de vida singular, mas todas tinham algo em comum: a rua. Uma palavra e lugar que deixou de ter um significado de movimento e encontros, tornando-se um espaço que tornou esses sujeitos invisiveis, que os deixou sem esperanças e excluídos diante da sociedade ${ }^{1}$.

De acordo com De Lucca², viver na rua é um sofrimento morno, ininterrupto e silencioso, contínuo e não verbalizado. Essa população é considerada um incômodo por ser uma resistente presença em via pública, sendo vista como vidas sem valor, incorrigíveis e inúteis para o mundo. A rua é local que não oferece garantias, apenas indeterminações, em que suas vidas estão expostas e abandonadas.

Até mesmo diante do Estado essas pessoas não eram alcançadas pelas políticas públicas, pois, durante longos períodos, foram negligenciadas e não se possuíam dados e informações o suficiente para que fosse realizado algum trabalho que pudesse fornecer respostas para os problemas que se apresentavam ${ }^{1}$.

No Brasil, apenas no ano de 2009 ocorreu a construção do I Censo e Pesquisa Nacional sobre a População em Situação de Rua, realizado apenas em 71 municípios, e organizado pelo então Ministério do Desenvolvimento Social e Combate à Fome, após uma longa demanda por parte dos movimentos sociais. Essa ainda é a maior pesquisa realizada em âmbito nacional ${ }^{3}$. 
Também em 2009, foi instituído pelo Decreto Presidencial n. ${ }^{0} 7.053^{4}$ a Política Nacional para a População em Situação de Rua, reconhecendo, assim, sua existência para a sociedade e o Estado:

considera-se população em situação de rua 0 grupo populacional heterogêneo que possui em comum a pobreza extrema, os vínculos familiares interrompidos ou fragilizados e a inexistência de moradia convencional regular, e que utiliza os logradouros públicos e as áreas degradadas como espaço de moradia e de sustento, de forma temporária ou permanente, bem como as unidades de acolhimento para pernoite temporário ou como moradia provisória4.

Após anos, em nosso país, ainda não existem dados oficiais sobre esse grupo, visto que os censos demográficos são realizados coletando dados nos domicílios. Em 2016, houve uma nova tentativa de se realizar uma estimativa, pois os números apresentados já não abrangiam a realidade daquele momento. Essa nova pesquisa foi realizada por intermédio dos dados fornecidos pelos próprios municípios, que retiravam esses números dos seus Censos dos serviços executados pela Assistência Social ${ }^{3}$.

Em 2020, realizou-se uma nova estimativa, dessa vez, além dos dados fornecidos pelas pesquisas realizadas pelos municípios, também foram acrescentadas as pessoas em situação de rua que estão sendo inseridas no Cadastro Único, possibilitando uma melhoria dos dados. Nessa estimativa, observou-se o aumento de $140 \%$ no período de 2012 a 2020 dessa população ${ }^{5}$.

Apesar de existir a proposta de que no próximo Censo realizado pelo Instituto Brasileiro de Geografia e Estatística (IBGE) também sejam contabilizadas as pessoas em situação de rua, um teste executado na cidade do Rio de Janeiro mostrou que há muitas dificuldades para que seja incluso esse público na pesquisa, principalmente por haver uma necessidade na mudança da metodologia-padrão utilizada atualmente ${ }^{3}$.

Nos últimos 11 anos persiste a dificuldade desse público em ter acesso aos equipamentos sociais, pois ainda há uma burocratização em que exigem documentação de pessoas que estão fora do sistema social. Além de existir uma rede fragilizada que, muitas vezes, não se apresenta capacitada para guiar essa pessoa em situação de rua pelos serviços ${ }^{6}$.

Então, este estudo torna-se relevante por tratar de uma questão de saúde pública e social, em razão de que essa população está mais vulnerável ao adoecimento mental e físico, exposta à violência e à pobreza extrema?

Portanto, esta pesquisa tem como objetivo discutir sobre a produção científica que tem sido produzida acerca das pessoas em situação de rua.

\section{METODOLOGIA}

A presente pesquisa é caracterizada como um estudo de abordagem qualitativa, realizada por meio de uma revisão narrativa da literatura, a qual tem caráter inventariante e descritivo, em que se busca agrupar em categorias o tema investigado e analisá$10^{8}$, pois, se queremos produzir práticas sociais que tenham a dimensão do coletivo, temos que dialogar com saberes múltiplos, temos que pesquisar e pesquisar com qualidade ${ }^{9}$.

A revisão consiste em um levantamento bibliográfico sobre determinado assunto, em que os resultados obtidos por outros autores serão descritos, interpretados e utilizados para fundamentar e atualizar o conhecimento sobre a temática durante uma análise crítica do(a) autor $(a)^{10}$. A pesquisa teve o intuito de discutir sobre quem era essa população em situação de rua, em que circunstâncias chegaram e se adaptaram, além de delinear quais ações estão sendo realizadas pelo governo e quais políticas públicas estão atuando para atender a esse público. Além disso, a relevância deste estudo justifica-se pela importância em compreender como as referidas informações estão sendo obtidas e processadas pelos pesquisadores por meio da análise de sua metodização nos trabalhos científicos acerca da população em situação de rua.

A produção de dados ocorreu entre junho e agosto de 2020. A fonte das produções científicas foi o sítio eletrônico Biblioteca Virtual em Saúde (BVS), em que se encontram indexadas as bases de dados Literatura Latino-Americana e do Caribe em Ciências da Saúde (LILACS), Sistema Online de Busca e Análise de Literatura Médica (MEDLINE), entre outros. Realizouse a busca utilizando a associação dos Descritores em Ciências da Saúde (DeCS): "pessoas em situação de rua"; "política pública" e "vulnerabilidade social", com a utilização do marcador booleano "and".

Os critérios de inclusão foram trabalhos publicados entre 2010 e 2020, com o intuito de 
mapear as publicações após a instituição da Política Nacional para a População em Situação de Rua (PNPSR), publicações no idioma português e relacionadas ao tema. A busca foi realizada resultando em 187 estudos, sendo eles 162 artigos, dez teses, uma monografia e 14 manuais.

Portanto, feita a leitura do resumo de todos os estudos e, em alguns casos, a apreciação dos resultados e discussões para se ter um melhor entendimento da pesquisa, definiram-se como critérios de exclusão: os trabalhos que não estavam disponíveis na íntegra, manuais do Ministério da Saúde e das Secretarias de Saúde com recomendações para os profissionais da saúde sobre o novo coronavírus, textos com títulos somente em inglês, arquivos duplicados no portal e os que não se apresentaram pertinentes para esta revisão. Desse modo, destacaram-se 33 publicações, as quais foram lidas na íntegra, e selecionadas 12 pesquisas para este estudo.

Os resultados serão apresentados por meio da exposição dos artigos escolhidos, além de pontuar os assuntos de acordo com o período das publicações, focando-se nos temas mais recorrentes. Serão sinalizadas as revistas de origem, os tipos de estudos e a sistematização realizada.

\section{RESULTADOS}

Das 12 publicações eleitas, todas são de abordagem qualitativa, e o ano de 2019 apresentou a maior produção científica, sendo seguido por 2018 e 2016. Porém, apenas 33,33\% são dos primeiros cinco anos examinados, pois nesses anos há uma menor quantidade de pesquisas relacionadas ao tema voltadas para as discussões sociais, enquanto a maioria discutia a associação de pessoas em situação de rua com Síndrome da Imunodeficiência Adquirida (Aids) ou relacionadas ao uso de drogas lícitas e ilícitas

Nos demais anos, as temáticas mais presentes ainda possuíam uma inclinação para conectar essa população ao uso de alguma substância psicoativa ou enfermidade, entretanto utilizando de outras referências, como saúde mental, Consultório na Rua e o tratamento da tuberculose. Além de temáticas que foram menos exploradas, como a relação com seus animais de estimação; o tratamento de câncer; envelhecimento; criança e adolescente; Lésbicas, Gays, Bissexuais, Transexuais, Travestis, Transgêneros, Queer, Intersexuais, Assexuais e mais (LGBTQIA+); mulher; gestação e pré-natal.

Dos anos de 2010 a 2019, houve a seleção de, no mínimo, uma publicação por ano, com exceção dos anos de 2011 e 2012, em virtude das poucas produções e pelo fato de que não se adequavam ao objetivo da pesquisa. Após leituras aprofundadas, os artigos foram fichados e organizados através da utilização de 17 palavraschaves mais recorrentes nos textos, empregues para nortear as discussões nos três eixos temáticos: perfil, motivação para rua, trabalho, tempo na rua, violência, família, novas relações, mulher, envelhecimento, ações, acesso, consultório na rua, acolhimento/cuidado, rua, políticas públicas, doenças e saúde mental.

Quadro 1. Caracterização dos estudos quanto ao título, ano, revista, autores e tipo de estudo.

\begin{tabular}{|c|c|c|c|c|c|}
\hline$N^{\circ}$ & TÍTULO & ANO & REVISTA & AUTORES & TIPO DE ESTUDO \\
\hline 1 & Quem mandou ficar velho e morar na rua? & 2010 & $\begin{array}{l}\text { Rev esc } \\
\text { enferm }\end{array}$ & Bretas et al. & Estudo de caso \\
\hline 2 & $\begin{array}{l}\text { Uma casa sem teto: influência da família } \\
\text { na vida das pessoas em situação de rua. }\end{array}$ & 2013 & $\begin{array}{l}\text { Ciênc cuid } \\
\text { saúde }\end{array}$ & $\begin{array}{l}\text { Marchi, } \\
\text { Carreira, Salci }\end{array}$ & $\begin{array}{l}\text { Descritivo- } \\
\text { exploratório }\end{array}$ \\
\hline 3 & $\begin{array}{l}\text { A rua tem um ímã, acho que é a liberdade: } \\
\text { potência, sofrimento e estratégias de } \\
\text { vida entre moradores de rua na cidade de } \\
\text { Santos, no litoral do Estado de São Paulo. }\end{array}$ & 2014 & Saúde Soc & $\begin{array}{l}\text { Andrade, } \\
\text { Costa, } \\
\text { Marquetti }\end{array}$ & Pesquisa social \\
\hline 4 & $\begin{array}{l}\text { Consultório na Rua: visibilidades, } \\
\text { invisibilidades e hipervisibilidade. }\end{array}$ & 2015 & $\begin{array}{l}\text { Cad saúde } \\
\text { pública }\end{array}$ & $\begin{array}{l}\text { Hallais, } \\
\text { Barros }\end{array}$ & $\begin{array}{l}\text { Observação } \\
\text { participante }\end{array}$ \\
\hline 5 & $\begin{array}{l}\text { As rupturas sociais e o cotidiano de pessoas } \\
\text { em situação de rua: estudo etnográfico. }\end{array}$ & 2016 & $\begin{array}{l}\text { Rev gaúcha } \\
\text { enferm }\end{array}$ & Fiorati et al. & Etnográfico \\
\hline 6 & $\begin{array}{l}\text { Direito à saúde da população em situação } \\
\text { de rua: reflexões sobre a problemática. }\end{array}$ & 2016 & $\begin{array}{l}\text { Ciênc saúde } \\
\text { colet }\end{array}$ & Paiva et al. & $\begin{array}{l}\text { Revisão } \\
\text { integrativa }\end{array}$ \\
\hline
\end{tabular}




\begin{tabular}{|c|c|c|c|c|c|}
\hline 7 & $\begin{array}{c}\text { Atenção à saúde da população em situação } \\
\text { de rua: um desafio para o Consultório na } \\
\text { Rua e para o Sistema Único de Saúde. }\end{array}$ & 2017 & $\begin{array}{l}\text { Cad saúde } \\
\text { pública }\end{array}$ & $\begin{array}{l}\text { Abreu, } \\
\text { Oliveira }\end{array}$ & $\begin{array}{l}\text { Não citado pelos } \\
\text { autores }\end{array}$ \\
\hline 8 & $\begin{array}{c}\text { Encontros na rua: possibilidades de saúde } \\
\text { em um consultório a céu aberto. }\end{array}$ & 2018 & Interface & $\begin{array}{l}\text { Santos, } \\
\text { Ceccim }\end{array}$ & Cartografia \\
\hline 9 & $\begin{array}{l}\text { Por um devir de bicicleta no apoio à rede } \\
\text { de saúde. }\end{array}$ & 2018 & Psicol soc & $\begin{array}{l}\text { Londero, } \\
\text { Paulon }\end{array}$ & $\begin{array}{l}\text { Pesquisa- } \\
\text { intervenção } \\
\text { cartográfica }\end{array}$ \\
\hline 10 & $\begin{array}{l}\text { MARIA, MARIA: concepções sobre ser } \\
\text { mulher em situação de rua. }\end{array}$ & 2019 & $\begin{array}{l}\text { Textos } \\
\text { contextos }\end{array}$ & $\begin{array}{l}\text { Sanchotene, } \\
\text { De Antoni, } \\
\text { Munhós }\end{array}$ & Exploratório \\
\hline 11 & $\begin{array}{c}0 \text { acesso da população em situação de rua } \\
\text { é um direito negado? }\end{array}$ & 2019 & REME & Lira et al. & Qualitativo \\
\hline 12 & $\begin{array}{l}\text { Atenção psicossocial e o cuidado em } \\
\text { saúde à população em situação de rua: } \\
\text { uma revisão integrativa. }\end{array}$ & 2019 & $\begin{array}{l}\text { Ciênc saúde } \\
\text { colet }\end{array}$ & Wijk, Mangia & $\begin{array}{l}\text { Revisão } \\
\text { integrativa }\end{array}$ \\
\hline
\end{tabular}

Fonte: Dados da pesquisa.

As publicações apresentadas foram organizadas no quadro por ordem crescente de ano, assinalando seus autores e as revistas de onde foram retirados os artigos. Houve uma tendência de periódicos relacionados à Saúde Coletiva, Saúde Pública e Enfermagem. Em relação aos tipos de estudo, estes foram citados de acordo com o informado pelos pesquisadores, em suas metodologias, trazendo uma rica diversidade de abordagens.

As informações analisadas nos artigos foram organizadas em três eixos temáticos: "Sinto muito, ela não mora mais aqui" ${ }^{11}$, no qual a população em situação de rua foi caracterizada; "Olha o tumulto: Façam fila por favor" 12, sobre as ações, acesso e as políticas públicas; e "Não temos tempo a perder"13, voltado para a saúde mental e os consultórios na rua.

Por fim, observa-se que o título "Não há verdades nem mentiras aqui"14, assim como as designações das subseções da discussão, faz referência a canções do álbum musical "Dois", da banda brasileira Legião Urbana. Esses trechos foram inspiração para a organização dos itens supramencionados.

\section{DISCUSSÃO}

\section{Sinto muito, ela não mora mais aqui}

Em 2009, foi realizada a Pesquisa Nacional sobre a População em Situação de Rua $^{1}$ e traçado o perfil dessas pessoas. Por meio da análise dos estudos realizados nos anos seguintes, os dados obtidos fortalecem e concordam com a Pesquisa Nacional, apontando para a sua maior parcela ainda ser predominante do sexo masculino e na faixa etária considerada como produtiva para a sociedade. Todavia, a permanência na rua apresentou, em média, ser superior a cinco anos, indicador que aumentou desde a pesquisa; o que é um alerta, uma vez que, quanto maior o tempo que a pessoa se encontra em situação de rua, menores as chances de conseguir superar essa condição $0^{15}$.

Marchi ${ }^{15}$ e Fiorati ${ }^{16}$ trazem uma discussão quando indicam o alto índice de desvinculação com parentes e sobre as relações com a família como uma das motivações para se estar na rua. Apesar de o uso de drogas surgir como principal motivação, é necessário perceber que há a sua influência no contexto familiar, podendo acarretar desentendimentos e expulsão do lar. E até mesmo ter sido ocasionado devido ao fato de já estarem inseridos em um ambiente de vulnerabilidade social, o qual serviu como determinante histórico que os condicionaram para as suas atuais conjunturas de vida.

Com o aprofundamento da análise, surgem outros fatores importantes, tais como: o abandono, a morte do provedor da renda familiar ou sua privação de liberdade em instituições prisionais, a perda do emprego ou de suas outras fontes de remuneração, o rompimento de laços afetivos com o divórcio, o ingresso de novos companheiros de genitores e atritos entre familiares. A violência também se manifesta como uma das razões, por meio de agressão 
física, moral e abuso sexual dentro dos lares, sendo a violência doméstica a principal causa da saída da mulher para as ruas ${ }^{16,17}$.

Pesquisar e compreender essas motivações é um dos passos iniciais para se desenvolver ações e políticas públicas que previnam a saída de outras pessoas de suas casas, promovendo meios de mediações para esses conflitos e ofertando oportunidades de superação para aqueles que já estão em vulnerabilidade ${ }^{15}$.

Ser da rua ultrapassa residir em logradouros públicos e utilizar de seus meios para a subsistência. A rua é um espaço pulsante que possui sua própria estrutura, com regras e códigos implícitos que se tornam essenciais para a sobrevivência ${ }^{5,18}$. É conviver com o medo, ser roubado, ter seu corpo exposto às mais diversas violências, sofrer preconceito, ter seus direitos negados pela sociedade e ser estigmatizado ${ }^{16,19}$.

Diante dessas experiências, emergem novas relações e estratégias de proteção. Constróise uma singular rede de suporte e vínculos de amizade com outras pessoas que se encontram nas ruas, objetivando-se enfrentar em conjunto os riscos e adversidades. Uma das táticas é evitar dormir sozinhos, criando apoio e cuidado mútuos. No entanto, ainda há aqueles que preferem vagar sozinhos ${ }^{15,18}$.

Historicamente, as mulheres estão mais suscetíveis à violência; nas ruas, isso é acentuado. Geralmente, elas procuram se associar a alguma figura masculina na busca de anteparo, e, em situação de precariedade, submetem-se a serem exploradas e trocam favores sexuais por alimento e objetos. Sendo a minoria, as mulheres buscam fortalecer a união feminina como confrontação ${ }^{17}$.

Para garantir o seu sustento, grande parte dessa população exerce atividade remunerada. Peregrinam próximos às zonas comerciais e com grande fluxo de pessoas no intuito de exercer funções como vigia de carro, descarga de caminhões e pequenos "bicos". A coleta de material reciclável é uma dessas principais ocupações, de modo que muitos são vistos puxando carroças carregadas pela cidade. Como essas atividades exigem da força física, é evidenciado que nem todos possuem capacidade funcional para realizá-las, principalmente o(a) idoso(a) ${ }^{19}$.

Os dados acusam que há uma baixa expectativa de vida dessa população e que ela é alvo de assassinatos, de doenças que foram adquiridas na rua ou agravadas nessas condições ${ }^{16}$. No entanto, ocorre o aumento do fenômeno do envelhecimento do povo de rua. São pessoas que não conseguiram reverter sua situação ou não quiseram e que agora estão com sua capacidade de autocuidado limitada, uma vez que sua saúde e capacidade física se fragilizam com o passar dos anos e nem sempre conseguem ter acesso aos seus benefícios sociais ${ }^{19}$.

\section{Olha o tumulto: Façam fila por favor}

As ações realizadas pelo Estado foram caracterizadas como fiscalizadoras, punitivas e de controle, as quais não visavam beneficiar nem reconhecer socialmente a população em situação de rua, excluindo-a enquanto moradores da cidade. 0 s agentes de segurança não tinham como um de seus papéis resguardá-los(as), mas proteger todas as outras pessoas daqueles que estavam em situação de rua. 0s seus poucos pertences eram retirados, sua documentação perdida, suas casas improvisadas eram derrubadas e os forçavam a sair da área em que estavam para promover a higienização e revitalização dos espaços públicos que eram degradados por sua permanência ${ }^{5,18,20}$.

As ofertas assistenciais das instituições também são taxadas como reguladoras em consequência de suas regras, das famílias que são separadas por sexo e idade, da imposição de convivência com desconhecidos, da falta de privacidade, da sua autonomia limitada com todos os seus horários determinados e até mesmo a insegurança de sofrer alguma violação ou perda dos seus objetos dentro do local ${ }^{18,19}$. Portanto, antes da criação de políticas públicas para um segmento populacional, devese conhecer sua heterogeneidade, suas histórias, particularidades e suas reais necessidades para que possam ser concebidas alternativas que sejam de natureza de inclusão e não de cerceamento e opressão $0^{18}$.

A invisibilidade dessa população é reforçada quando o seu acesso aos serviços e benefícios é dificultado por diversos fatores, por mais que a universalidade de acesso aos atendimentos seja garantida desde a Constituição de $1988^{5,21}$. A barreira já começa na porta de entrada. Quando não se têm documentos e comprovante de endereço para realizar os cadastros, a burocracia desanima a busca desse serviço - mais um "não" na infinidade dos que já lhes foram ditos ${ }^{5,22}$.

Quando conseguem garantir o primeiro atendimento, estes geralmente são de urgência, 
emergência e pontuais. Não há uma continuidade do acompanhamento da sua situação de saúde ou a comunicação da rede socioassistencial com os demais serviços. Isso dificulta a criação de vínculos do(a) sujeito(a) com a unidade e a responsabilização para o cuidado. 0 pouco conhecimento da Política Nacional não é só por parte dos(as) usuários(as). Muitos(as) profissionais de saúde não possuem entendimento dos direitos ou até mesmo está velado o seu preconceito 21 .

0 acolhimento é uma estratégia para superar as barreiras, é um ponto de encontro com os(as) usuários(as), em que há uma troca de saberes e respeito, visando não só à agudização do seu atual problema, mas à busca, em suas histórias, dos significados e da promoção do cuidado ${ }^{5}$. 0 trabalho em equipe e o matriciamento com os demais serviços são os meios que permitem a visão integral da pessoa rompendo com o modelo médico-centrado. 0 compartilhamento dos conhecimentos/saberes aprimora os atendimentos ${ }^{23}$.

A população em situação de rua não quer só sobreviver em circunstâncias precárias, não quer ser culpabilizada por suas condições de vida. Ela quer ser reconhecida como cidadã, quer moradia, saúde, trabalho, família, alimentação de qualidade, educação e que seus direitos sejam válidos ${ }^{20}$. Para isso, necessita-se de planejamento, organização e gestão de políticas sociais setoriais que garantam 0 acesso ${ }^{24}$.

\section{Não temos tempo a perder}

Nas produções científicas, a saúde mental se mostrou presente, no entanto, focaram no uso de drogas por parte da população em situação de rua. Em alguns casos, evidenciaram o agravo das pessoas que têm transtornos mentais, as dificuldades para o tratamento e o uso da medicação, causando o abandono do acompanhamento ${ }^{23}$. Um dos aliados da Rede de Atenção Psicossocial são as equipes do Consultório na Rua ${ }^{25}$, as quais atuam como uma extensão da Atenção Primária, sendo o tema de maior recorrência nas pesquisas dos últimos seis anos.

0 Consultório na Rua é um trabalho vivo, itinerante, que percorre e adentra territórios para ir ao encontro de seu público fora dos espaços institucionais, com uma dinâmica de desterritorialização. É uma proposta de ampliação do acesso e de aproximação para a criação de vínculos e empatia que facilitem a escuta, os cuidados primários em saúde, a redução de danos e apoio socioassistencial ${ }^{5,22,26}$.

Os modos do trabalho do Consultório na Rua são singulares, fora do padrão hegemônico de localidade, em que o usuário precisa ir em busca desse atendimento. E com profusa procura que não pede só o cuidado, mas também o afeto, suporte e perspectivas. Um desafio ao apresentar a oferta de olhar para essa população a partir de um novo ângulo, dentro do ambiente onde são negados os seus direitos e sendo um serviço de resistência ${ }^{5,22,26}$.

Como o Consultório na Rua possui uma demanda complexa, o compartilhamento de ações e o fortalecimento dos laços interdisciplinares são imprescindíveis, valorizando a educação permanente e as discussões dos $\operatorname{casos}^{24}$. Entretanto, nem sempre conseguem solucionar os problemas apenas em seu meio, por isso funcionam como rede e fazem a ligação com os demais serviços, redirecionando para outras unidades mais próximas ${ }^{5}$.

Santos e Ceccim² ${ }^{24}$ aludem sobre essa clínica montada a céu aberto e que não oferta consultas, e sim olhares, escutas e falas; realiza encontros, mas não qualquer encontro, é a reunião de afetos. É a imersão na subjetividade, a problematização e o entrelaçar de vozes. Ressignificar vivências para conceber possibilidades, tornando essa estratégia uma potência por reinventar o cuidado.

\section{CONCLUSÃO}

Identificou-se nesta pesquisa que a produção científica sobre a população em situação de rua ainda é tímida. Os primeiros anos ainda foram voltados para o corpo e doença, sem se entranhar em seu íntimo, enquanto focam nos estigmas como as drogas. Sobre gênero, sexualidade e geração, seus dados são escassos, principalmente em relação às crianças e adolescentes, já que os estudos, em sua maior parte, são feitos com pessoas acima dos 18 anos - até mesmo a pesquisa realizada pelo governo não produziu números oficiais acerca dessa faixa etária.

0 envelhecimento é pautado, embora não se aprofundem nesse fenômeno, trazendo questionamentos se todos os idosos encontrados apenas envelheceram nesse ambiente ou ingressaram na rua já nessa idade devido às desigualdades sociais e ao fato de a sociedade não estar preparada para quem envelhece.

As particularidades sobre a sexualidade não são exploradas, demonstrando que o público LGBTQIA+ 
é constante alvo de preconceitos e de conflitos familiares por falta de aceitação, gerando, muitas vezes, quebra dos laços afetivos. Assim como questões de gênero, em que mulheres, travestis e transexuais são focos de violências no cotidiano e que se intensificam nas ruas.

Concluiu-se que os dados obtidos são genéricos e as suas discussões eram voltadas paras as políticas de saúde que estavam sendo discutidas no seu período, sendo necessário evidenciar essa lacuna e incentivar que pesquisadores vejam a rua como fonte de relações e subjetividades que precisam ser examinadas e conhecidas, além de pressionar para que as políticas públicas direcionadas a essa população sejam implementadas com qualidade.

\section{CONTRIBUIÇÃO DAS AUTORAS}

Larissa de Andrade Carmo contribuiu com o delineamento, a realização da pesquisa e a redação do manuscrito. Jhennifer de Souza Góis contribuiu com o delineamento da pesquisa e a revisão crítica do manuscrito.

\section{REFERÊNCIAS}

1. Brasil. Rua: aprendendo a contar: Pesquisa Nacional sobre a População em Situação de Rua. Brasília (DF): Ministério do Desenvolvimento Social e Combate à Fome; 2009.

2. De Lucca D. Morte e vida nas ruas de São Paulo: a biopolítica vista do centro. In Rui T, Martinez M, Feltran G, organizadores. Novas faces da vida nas ruas. São Carlos: EdUFSCar; 2016. p. 19-43.

3. Natalino MAC. Estimativa da população em situação de rua no Brasil. Brasília (DF): Ipea; 2016.

4. Brasil. Decreto Presidencial $n^{0}$ 7.053, de 23 de dezembro de 2009. Institui a Política Nacional para a População em Situação de Rua e seu Comitê Intersetorial de Acompanhamento e Monitoramento, e dá outras providências. Diário Oficial da União; Seção 1, 24 dez. 2009.

5. Natalino MAC. Estimativa da população em situação de rua no Brasil (setembro de 2012 a março de 2020). Brasília (DF): Ipea; 2020.

6. Hallais J, Barros N. Consultório de rua: visibilidades, invisibilidade e hipervisibilidade. Cad saúde pública [serial on the internet]. 2015 [cited 2020 Jun 05]; 31(7):1497-1504. Available from: http://www.scielo.br/scielo.php?script=sci arttext\&pid $=$ S0102-311X2015000701497\&lng =en
7. Santana CL, Rosa AS. Saúde mental das pessoas em situação de rua: conceitos e práticas para profissionais da assistência social. São Paulo: Epidaurus Medicina e Arte; 2016.

8. Ferreira NSA. As pesquisas denominadas "estado da arte". Educ Soc [serial on the internet]. 2002 [cited 2020 May 09]; 23(79):257-72. Available from: http://www.scielo.br/scielo.php? script $=\mathrm{sci}$ arttext \& pid $=S 0101$ 73302002000300013\&lng $=$ en $\&$ nrm $=$ iso

9. Martinelli ML. Pesquisa Qualitativa: um instigante desafio. São Paulo: Veras; 1999.

10. Rother ET. Revisão sistemática $X$ revisão narrativa. Acta paul enferm [serial on the internet]. 2007 [cited 2020 May 09]; 20(2):v-vi. Available from: http://www.scielo.br/scielo.php?script=sci arttext\&pid $=$ S0103-21002007000200001\&lng =em

11. Villa-Lobos D, Russo R, Rocha R. Bonfá M. Acrilic on Canvas. In Legião Urbana. Dois [álbum musical]. Brasil: EMI - Odeon; 1986. Áudio: 4:40 $\min$.

12. Russo R. Metrópole. In Legião Urbana. Dois [álbum musical]. Brasil: EMI - Odeon; 1986. Áudio: $2: 50 \mathrm{~min}$.

13. Russo R. Tempo Perdido. In Legião Urbana. Dois [álbum musical]. Brasil: EMI - Odeon; 1986. Áudio: 5 min.

14. Russo R. Música Urbana 2. In Legião Urbana. Dois [álbum musical]. Brasil: EMI - Odeon; 1986. Áudio: $2: 42 \mathrm{~min}$

15. Marchi JA, Carreira L, Salci MA. Uma casa sem teto: influência da família na vida das pessoas em situação de rua. Ciênc cuid saúde [serial on the internet] 2013 [cited 2020 Aug 01]; 12(4):6407. Available from: https://periodicos.uem.br/ojs/ index.php/CiencCuidSaude/article/view/22554/ pdf 60

16. Fiorati RC, Carreta RYD, Kebbe LM, Cardoso BL, Xavier JJS. As rupturas sociais e o cotidiano de pessoas em situação de rua: estudo etnográfico. Rev gaúcha enferm [serial on the internet]. 2016 [cited 2020 Aug 01]; 37(spe):e72861. Available from: http://www.scielo.br/scielo .php? script =s ci arttext\&pid=S1983$14472016000500427 \& \operatorname{lng}=$ en

17. Sanchotene IP, De Antoni C, Munhós AAR. MARIA, MARIA: concepções sobre ser mulher em situação de rua. Textos contextos [serial on the internet]. 2019 [cited 2020 Aug 03]; 18(1):14660. Available from: https://www.researchgate.net/ deref/http \%3A\%2F\%2Fdx.doi.org\%2F10.15448\% 2F1677-9509.2019.1.29297 
18. Andrade LP, Costa SL, Marquetti FC. A rua tem um imã, acho que é a liberdade: potência, sofrimento e estratégias de vida entre moradores de rua na cidade de Santos, no litoral do Estado de São Paulo. Saude Soc [serial on the internet]. 2014 [cited 2020 Aug 03]; 23(4):1248-61. Available from: http://www. scielo.br/scielo.php? script $=$ sci arttext $\&$ pid $=$ S0104$12902014000401248 \& \operatorname{lng}=$ en

19. Bretas ACP, Brêtas ACP, Marcolan JF, Rosa AS, Fernandes FSL, Raizer MV. Quem mandou ficar velho e morar na rua? Rev esc enferm USP [serial on the internet]. 2010 [cited 2020 Aug 04]; 44(2):476-81. Available from: http://www.scielo. br/scielo.php?script $=$ sci arttext\&pid $=S 0080-$ $\underline{62342010000200033 \& \operatorname{lng}=e n}$

20. Paiva IKS, Lira CDG, Justino JMR, Miranda MG0, Saraiva AKM. Direito à saúde da população em situação de rua: reflexões sobre a problemática. Ciênc saúde colet. [serial on the internet]. 2016 [cited 2020 Aug 04]; 21(8):2595-2606. Available from: http://www.scielo.br/scielo . php?script =sci arttext\&pid =S1413$81232016000802595 \& \operatorname{lng}=$ en

21. Lira C, Justino JM, Paiva IK, Miranda M, Saraiva AK. 0 acesso da população em situação de rua é um direito negado? REME [serial on the internet]. 2019 [cited 2020 Aug 06]; 23:e1157. Available from: http:// www.dx.doi.org/10.5935/1415-2762.20190004

22. Londero MFP, Paulon SM. Por um devir de bicicleta no apoio à rede de saúde. Psicol Soc [serial on the internet]. 2018 [cited 2020 Aug 06]; 30:e169755. Available from: http://www.scielo.br/ scielo.php? script $=$ sci arttext \&pid $=$ S010271822018 $000100212 \& \operatorname{lng}=$ en \& $n r m=$ iso

23. Wijk LBV, Mangia EF. Atenção psicossocial e o cuidado em saúde à população em situação de rua: uma revisão integrativa. Ciênc saúde colet [serial on the internet]. 2019 Sep [cited 2020 Aug 07]; 24(9):3357-68. Available from: http://www.scielo. br/scielo.php?script=sci arttext\&pid=S1413-812 $\underline{32019000903357 \& \operatorname{lng}=\text { en }}$

24. Santos CF, Ceccim RB. Encontros na rua: possibilidades de saúde em um consultório a céu aberto. Interface (Botucatu) [serial on the internet]. 2018 [cited 2020 Aug 07]; 22(67):1043-52. Available from: http://www.scielo.br/scielo.php?script=sci arttext\&pid $=$ S1414-32832018000401043\&lng=en

25. Brasil. Portaria no 122, de 25 de janeiro de 2012: define as diretrizes de organização e funcionamento das equipes de Consultório na Rua. Diário Oficial da União; 2012.

26. Abreu D, Oliveira WF. Atenção à saúde da população em situação de rua: um desafio para - Consultório na Rua e para o Sistema Único de Saúde. Cad saúde pública [serial on the internet]. 2017 [cited 2020 Aug 09]; 33(2):e00196916. Available from: http://www.scielo.br/

scielo.php?script $=$ sci arttext \&pid=s0102311X2017000207001\&lng $=p t$
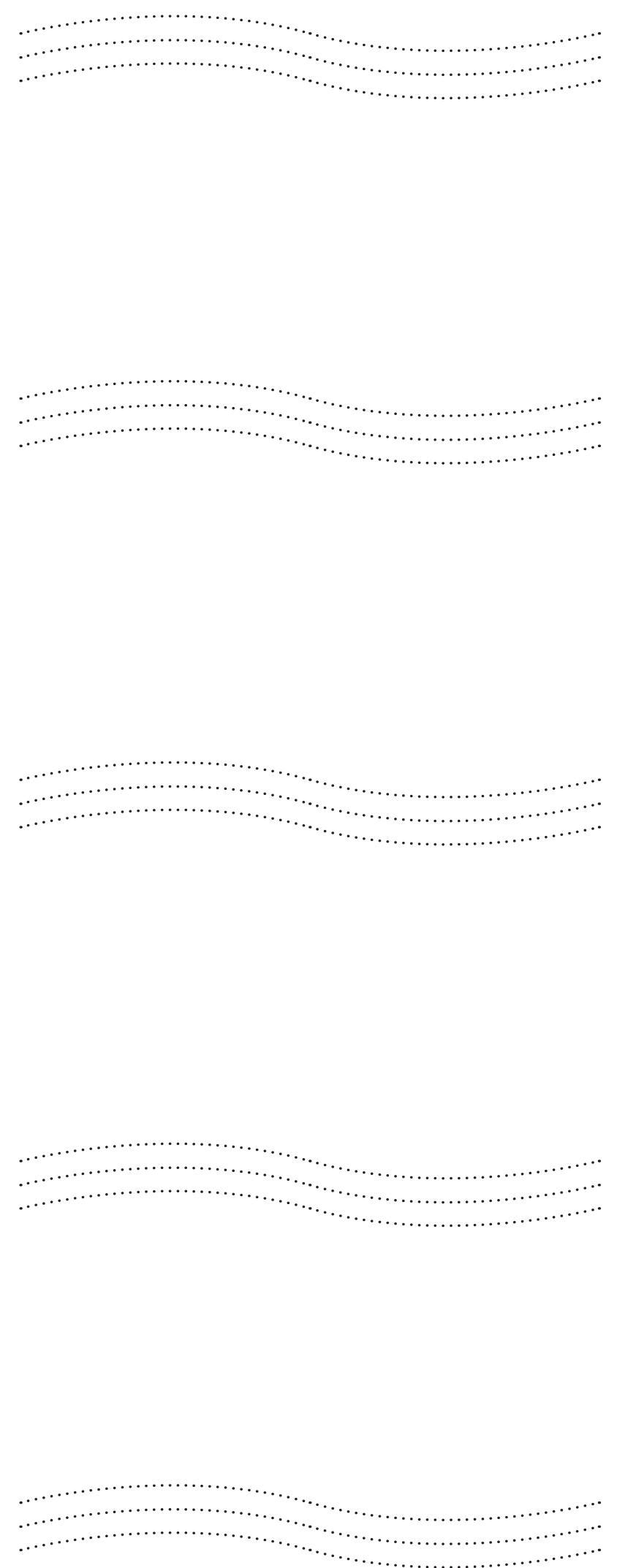